\title{
SEMPRE CRESCE, QUEM COOPERA?
}

\author{
ALWAYS GROWS, WHO COOPERATES?
}

FERNANDA SILVEIRA

Universidade do Vale do Itajaí (UNIVALI)

Especialista em Finanças Empresariais

Orcid: https://orcid.org/0000-0003-0712-181X / E-mail: fersilveira@outlook.com.br

THAMARA GABRIELLE DA VEIGA

Universidade do Vale do Itajaí (UNIVALI)

Especialista em Finanças Empresariais

Orcid: https://orcid.org/0000-0002-6404-4454 / E-mail: Thamaragabrielle@hotmail.com

\author{
ELEANDRA MARIA PRIGOL MENEGHINI \\ Universidade do Vale do Itajaí (UNIVALI) \\ Mestranda em Administração \\ Orcid: https://orcid.org/0000-0002-2961-882X / E-mail: eleandra.meneghini@gmail.com \\ Rua da Universidade, no 89, Apto. 504 Torre A \\ Bairro Pedra Branca - Palhoça SC - CEP 88137074
}

\author{
JEFERSON LANA \\ Universidade do Vale do Itajaí (UNIVALI) \\ Professor do PPGA na Universidade do Vale do Itajaí (UNIVALI) \\ Orcid: https://orcid.org/0000-0002-9787-1114 / E-mail: jeff@rovian.com.br
}

\section{RESUMO}

As cooperativas de crédito visam alcançar o desenvolvimento financeiro e econômico aos associados, além de buscar prosperidade regional onde operam. A Cooperativa de Crédito Coopcred foi fundada por médicos em 1998, e se expandiu rapidamente chegando em 2018 com 12.000 associados, pessoas físicas e jurídicas das áreas da saúde, contábil, educação, construção civil e empresários em geral. Com perfis diferentes, Alfredo, o diretor financeiro, mais conservador, defendia a manutenção da tradição e cultura da cooperativa, e temia o risco de baixar as reservas cambiais da instituição, enquanto Jorge, o diretor executivo, de ideias arrojadas, defendia a implantação de novas tecnologias, ampliação e modernização das agências, sem medo de correr riscos. Após dois exercícios consecutivos de fechamento positivo e sobras a serem distribuídas aos associados, 2017 não foi animador, sem sobras a serem distribuídas. O caso visa proporcionar uma reflexão acerca da contabilidade gerencial de uma cooperativa de crédito, a fim de analisar as demonstrações contábeis para a tomada de decisões e gerenciamento de resultados. Propõe-se sua aplicação nas disciplinas de Contabilidade Gerencial e Administração Financeira, em cursos de graduação e pós-graduação em Administração e Ciências Contábeis.

Palavras-chave: Cooperativa de crédito. Demonstrações contábeis. Gerenciamento de resultados ${ }^{1}$.

1 Data de submissão: 04/02/2019. Data de aceite: 04/08/2019. Data de publicação: 13/08/2019. 


\begin{abstract}
The credit cooperatives aim to achieve the financial and economic development of the members, in addition to seeking regional prosperity where they operate. The Coopcred Credit Union was founded by physicians in 1998 and expanded rapidly in 2018 with 12,000 associates, individuals and legal entities from the health, accounting, education, construction and general business sectors. With different profiles, Alfredo, the more conservative financial director, defended the maintenance of the cooperative's tradition and culture, and feared the risk of lowering the institution's foreign exchange reserves, while Jorge, the executive director, with bold ideas, defended the implantation of new technologies, expansion and modernization of the agencies, without fear of taking risks. After two consecutive exercises of positive closure and leftovers to be distributed to members, 2017 was not encouraging, with no leftovers to be distributed. The case aims to provide a reflection about the managerial accounting of a credit union, in order to analyze the financial statements for the decision making and management of results. It is proposed to be applied in the areas of Management Accounting and Financial Management, in undergraduate and postgraduate courses in Administration and Accounting Sciences.
\end{abstract}

Keywords: Credit Cooperative. Accounting statements. Managing results.

\title{
1 INTRODUÇÃO
}

- Hoje é o dia D! - Exclamou Alfredo para si mesmo, acomodando-se em sua sala. Alfredo era o diretor financeiro da Cooperativa de Crédito Coopcred e estava na instituição desde sua fundação em 1998. Era janeiro de 2018, dia em que seria fechada a contabilidade do ano de 2017 e demonstrado o resultado daquele período. Alfredo estava com um pressentimento de que as coisas não seriam tão boas como foram nos últimos anos, já que as análises e comparativos que ele vinha fazendo, com o mesmo período dos anos anteriores, não eram animadoras. Na opinião de Alfredo, a cooperativa inovou demais, avançou demais, cresceu demais e esqueceu de cuidar das reservas financeiras.

Jorge, o diretor executivo, defendia a ideia de que nada mais era como antes. 0 mercado financeiro estava passando por transformações, novos concorrentes estavam surgindo e tinha uma posição muito tranquila quanto às análises e comparativos realizados pelo colega: "Calma Alfredo, isso é 'marolinha', não vai chegar na Coopcred. Nossa cooperativa cresce mais e mais a cada dia! Temos que inovar mais, avançar mais e assim vamos crescer mais!"

Alfredo e Jorge eram opostos como a água e o vinho. Alfredo era pé no chão, centrado, conservador. Já Jorge era visionário, dono de ideias inovadoras, voltado para automação dos processos e implantação de novas tecnologias. Alfredo queria manter a tradição e a cultura da cooperativa, orgulho dos associados mais antigos, Jorge queria implantar bases tecnológicas, inaugurar novas agências e modernizar as atuais.

Para Alfredo, tudo dependeria do resultado de 2017, prestes a sair. Se os resultados se confirmarem, ele teria que conter o colega e repensar as estratégias da Coopcred para recuperação e equilíbrio orçamentário em 2018.

Alfredo ligou seu notebook e lá estava o e-mail tão aguardado: o demonstrativo do resultado do exercício de 2017. Abriu os relatórios um a um já sentindo calafrios, era o que ele temia, infelizmente. Resolveu imprimir os relatórios e ligou para Jorge, os dois precisavam 
estar juntos naquele momento. Recostou-se na cadeira e seus pensamentos voaram para o momento em que ele e Jorge levariam esses dados para a Assembleia.

Os dois diretores eram responsáveis por justificar todas as operações da entidade para o presidente, vice-presidente, conselho fiscal e administrativo, bem como apresentar os resultados obtidos na Assembleia Geral Ordinária para os associados da cooperativa, pelo menos uma vez ao ano.

Jorge adentrou na sala de Alfredo com os relatórios em mãos e ambos concordaram em analisar juntos os números apresentados e traçar um comparativo com os planos aprovados para 2018. Eles precisavam entender o que realmente se passava com a Coopcred.

Conseguiriam Alfredo e Jorge superar as diferenças e construir uma visão conjunta da situação da Coopcred? Como seria a reação da Diretoria e dos Associados ao resultado de 2017 da cooperativa? Qual o melhor caminho para a Coopcred, manter a cultura que orgulhava os sócios mais antigos ou migrar para a era tecnológica, modernizando a cooperativa? Estaria afinal das contas, a Coopcred, passando por uma crise?

\section{A COOPCRED}

Fundada em 1998 por três médicos da região do Vale do Itajaí, que buscavam soluções financeiras e taxas de juros menores do que as adotadas pelos bancos tradicionais, a Coopcred era uma instituição financeira cooperativa, de natureza jurídica própria, não sujeita à falência e normatizada pela legislação cooperativista e pelo Sistema Financeiro Nacional.

Iniciou com quadro de associados formado por médicos e teve a primeira agência aberta no centro da cidade de Itajaí, Santa Catarina. Oferecia produtos e serviços tais como empréstimos, aplicações, cheque especial, saques, depósitos, pagamentos de títulos e convênios.

A cooperativa foi bem aceita pelos médicos, que abraçaram a ideia do cooperativismo. Desde o princípio, a cooperativa firmou parcerias com empresas da cidade, ligadas à área da saúde, como clínicas e hospitais, onde foi possível obter uma boa carteira de clientes que se mantiveram parceiros ao longo dos anos.

Com o passar do tempo, em 2005, a diretoria aprovou em assembleia, a abertura do quadro de associados para demais profissionais da área da saúde, assim como profissionais das áreas contábeis e da educação, e, mais tarde, já em 2010, visando um crescimento mais rápido, a diretoria chegou a um consenso em assembleia, de que a melhor estratégia para alcançar essa meta dentro do Sistema Financeiro Nacional seria a admissão de empresários como associados.

A Coopcred se firmava como destaque em qualidade de atendimento, onde o cooperado se dirigia às agências para algo mais do que fazer negócios, mas para simplesmente, tomar um café ou ler o jornal matinal da cidade e região. A Coopcred ganhou clientes fiéis devido à confiança adquirida e mostrou seu diferencial perante os concorrentes. Os associados orgulhavam-se em dizer que o atendimento ao público de forma amigável e atenciosa, era um ponto forte da Coopcred.

A Cooperativa seguia os sete princípios do cooperativismo, que são linhas orientadoras de ações para que as cooperativas coloquem em prática seus valores de democracia, liberdade, equidade, solidariedade e justiça social. Os princípios são: adesão livre e voluntária, gestão democrática, participação econômica, autonomia e independência, educação, formação e informação, intercooperação e interesse pela comunidade. Entre as vantagens de se tornar um cooperado da Coopcred estavam o fato de que nesta todos possuíam o mesmo 
poder de decisão, uma vez que eram os donos do negócio, bem como se ajudavam de forma mútua.

Alfredo fora contratado no ano da fundação da Coopcred e, no princípio era responsável por todas as atividades administrativas, galgou degraus e chegou ao posto de diretor financeiro. Era considerado um dos pilares do bom funcionamento e atendimento da cooperativa, visto por muitos cooperados como referência. Mas a história nem sempre foi assim, já que, no início, Alfredo não tinha experiência alguma nesse ramo e enfrentou várias dificuldades para gerir o negócio cooperativo. Entretanto, a tão necessária experiência foi sendo conquistada e Alfredo foi aprendendo com seus erros e acertos a gerenciar de fato uma cooperativa de crédito.

Jorge foi contratado em 2005, trazendo em sua bagagem experiência de mercado e conquistando espaço por meio de suas ideias inovadoras. $O$ diretor executivo tinha uma visão empreendedora e sabia aproveitar as oportunidades para transformar a cooperativa em uma organização competente e sólida dentro do Sistema Financeiro Nacional. Foi responsável por apresentar em assembleia e conseguir aprovação dos associados para os planos de expansão da Coopcred.

\section{CRISE FINANCEIRA: 'MAROLINHA' OU TSUNAMI?}

A partir de 2010, quando a busca pelo crescimento e acompanhamento do mercado financeiro fez com que a Coopcred optasse pela estratégia de admissão também de empresários como associados, os negócios foram crescendo vertiginosamente. Eram meados de 2012 e a cooperativa estava em ritmo acelerado de crescimento, mantendo a sua inadimplência controlada e contando com associados que já possuíam uma vida financeira estável e aplicações significativas.

Desta forma, a cooperativa que havia se consolidado no atendimento e na oferta de produtos e serviços para o segmento médico, começava a expandir seus horizontes e ampliar sua carteira de associados. Em 2013, as cooperativas de crédito tiveram um crescimento de $21 \%$, o que fez com que a expectativa para 2014 aumentasse.

Com o crescimento imobiliário, o mercado realmente estava a todo vapor, novos cooperados se associaram, pessoas jurídicas da área de construção civil, empresas de grande porte e empresas que prestavam serviços para o governo.

Realmente, os negócios iam de vento em popa, com o spread alto, em virtude das grandes liberações de empréstimo. Alfredo e Jorge estavam certos de sua tomada de decisão e felizes com os resultados obtidos. Tendo grandes empresas como associadas, existia também a necessidade de liberação de crédito em maiores proporções, entretanto, como os negócios iam muito bem, isso não era um problema para a Coopcred.

Os índices comprovaram que o ano de 2014 apresentou um crescimento ainda maior para as cooperativas, as quais tiveram um crescimento de $22 \%$, enquanto o Sistema Financeiro Nacional cresceu apenas $14 \%$.

Jorge executava seus planos de crescimento, abertura de novas agências, outras foram ampliadas e os negócios estavam muito satisfatórios, com os novos associados de "grande" potencial. Porém algo preocupante começava a acontecer em meados de 2014, a crise financeira nacional começava a dar seus sinais.

Chegou o ano de 2015, a Coopcred continuava seguindo seu planejamento financeiro, sem sentir a crise do mercado. Jorge seguia confiante e ampliava os negócios para o Paraná, ganhando mais força e conceito no mercado. 
Em 2016, o mercado sentiu a forte crise financeira, esperava-se uma redução do crescimento econômico, o crédito bancário começava a andar de lado, mas as cooperativas ainda continuavam avançando, porém em um ritmo bem menos acelerado, o reflexo no crescimento já era constatado nas informações repassadas pelo Banco Central, onde em 2016 foi de apenas $8 \%$, nada mais nada menos que $14 \%$ menor que o ano anterior.

Jorge e Alfredo se preocuparam, pois a inadimplência começava a aparecer, riscos e provisões altas seguiam meses consecutivos e em maior escala nos relatórios mensais. Seus cooperados já estavam sofrendo com a crise do mercado, demissões acontecendo em maior escala, queda nas vendas e escândalos políticos.

O ano de 2017 seguiu a mesma linha de 2016, baixa demanda de crédito, crescimento da inadimplência e grande volume de encerramento de contas com baixa de associados. Infelizmente, a crise chegou para a Coopcred e todo o crescimento obtido de forma acelerada de 2013 a 2015 estava refletindo também nos resultados do ano de 2017. Os diretores precisavam tomar decisões rápidas e de forma eficaz para não afetar a imagem da cooperativa junto aos cooperados e seus colaboradores e assim entrar em 2018 com solidez.

\section{NOVO MODELO DE MERCADO FINANCEIRO}

Jorge, como sempre, estava atento ao mercado e, apesar de sempre ter buscado oferecer um serviço diferenciado aos cooperados, andava ansioso com o que estava por vir, uma vez que os bancos tradicionais já buscavam adequação a este novo modelo de mercado financeiro. Jorge falava para Alfredo que eles deveriam focar mais nesse diferencial e tentar sair na frente das demais cooperativas, ganhando destaque e oferecendo um serviço de acordo com o mercado.

Alfredo, preocupado com os resultados da cooperativa, tentava acalmar Jorge:

- Jorge, a transformação e o investimento em tecnologia precisam ocorrer de forma cautelosa, afinal, já estamos dando alguns passos para a tecnologia, com atualizações de alguns serviços por aplicativo, reformulações no Internet Banking e em alguns processos e compra de novos equipamentos. Mas agora temos o complicador "crise" para tratar.

- Com os avanços da tecnologia, a crise é mais um dos fatores que vamos enfrentar na Coopcred. Desde 2012 que muitas transformações estão ocorrendo no mercado financeiro, a tecnologia tem conquistado seu espaço e trazendo um novo modelo de mercado para um dos setores mais importantes da economia. - respondeu Jorge, que prosseguiu.

- Trabalhar a situação mercadológica interna da instituição é fundamental para conhecermos nossa posição atual no mercado, e temos que estar atentos aos concorrentes, aos novos produtos e serviços, bem como atentos a quais são as tendências de mercado.

Alfredo concordou com Jorge. Ele sabia que precisavam criar ferramentas para manter a Coopcred com um diferencial competitivo junto aos seus concorrentes. Entretanto, para Jorge isso ainda era pouco se comparado às inovações e novas tendências que estavam chegando, como bancos digitais, fintechs e até mesmo com o estouro das moedas digitais no mercado.

Alfredo entendia as preocupações de Jorge, mas ressaltava que essa situação teria que ser revista e trabalhada junto ao grupo estratégico, pois existia a preocupação de como os cooperados mais antigos iriam reagir a essas mudanças tão bruscas que o mercado estava apresentando. Em contrapartida, existia a preocupação com os cooperados mais jovens, que têm absorvido as inovações da tecnologia, estavam muito ligados nos custos e serviços 
oferecidos pelas instituições e buscavam serviços que atendessem suas necessidades de forma prática e segura.

\section{A ASSEMBLEIA GERAL ORDINÁRIA}

A assembleia geral ordinária era o órgão máximo das cooperativas, suas deliberações deviam ser acatadas por todos os cooperados, inclusive os ausentes ou discordantes, privilegiando sempre o interesse coletivo.

Realizada uma vez ao ano, era responsável por discutir assuntos, entre os quais destacavam-se as prestações de contas, destinação das sobras apuradas ou rateio das perdas, eleição, posse e fixação do valor dos honorários e gratificações dos membros da Diretoria e dos Conselhos e outros de interesse dos associados.

É chegado o mês de abril de 2018, prazo para a assembleia da Coopcred. Jorge, Alfredo, e os demais membros da diretoria, além dos conselhos de administração e fiscal estudaram todos os temas de interesse dos cooperados e montaram a pauta da assembleia.

As assembleias foram sendo realizadas em núcleos para envolver os 12 mil cooperados e seus representantes se faziam presentes. O presidente Dr. Maurício deu início à assembleia, falando sobre a expansão da Coopcred no estado do Paraná, que foi próspera, explicando as novidades implantadas na cooperativa no ano de 2017, os novos sistemas e investimentos, e passou a palavra para Jorge, que fez uma introdução sobre a situação financeira do país, informando que a mesma também afetou a cooperativa. Logo após ele convidou Alfredo, para que iniciasse a prestação de contas.

Alfredo iniciou apresentando o balanço patrimonial da cooperativa, com os três últimos exercícios, no qual era possível acompanhar as variações patrimoniais da entidade no decorrer dos anos, conforme segue abaixo na tabela 1.

Tabela 1: Balanço Patrimonial

\begin{tabular}{|c|c|c|c|c|c|c|c|}
\hline Ativo & 2015 & 2016 & 2017 & Passivo & 2015 & 2016 & 2017 \\
\hline Circulante & 320.970 & 474.411 & 594.527 & Circulante & 558.293 & 681.606 & 773.689 \\
\hline Disponibilidades & 3.310 & 2.682 & 3.185 & Depósitos & 551.740 & 675.051 & 762.152 \\
\hline $\begin{array}{l}\text { Relações } \\
\text { interfinanceiras }\end{array}$ & 173.538 & 282.402 & 388.030 & $\begin{array}{l}\text { Relações } \\
\text { interfinanceiras }\end{array}$ & 0 & 0 & 243 \\
\hline $\begin{array}{l}\text { Operações de } \\
\text { crédito }\end{array}$ & 127.571 & 138.564 & 145.687 & $\begin{array}{l}\text { Outras } \\
\text { obrigações }\end{array}$ & 6.553 & 6.555 & 11.294 \\
\hline Outros Créditos & 998 & 6.668 & 4.334 & & & & \\
\hline $\begin{array}{l}\text { Outros valores e } \\
\text { Bens }\end{array}$ & 15.553 & 44.095 & 53.291 & & & & \\
\hline Não circulante & 350.838 & 329.651 & 307.514 & Não circulante & 3.044 & 5.155 & 7.010 \\
\hline $\begin{array}{l}\text { Operações de } \\
\text { crédito }\end{array}$ & 325.938 & 299.354 & 275.717 & $\begin{array}{l}\text { Outras } \\
\text { obrigações }\end{array}$ & 3.044 & 5.155 & 7.010 \\
\hline Outros créditos & 2.932 & 5.069 & 5.548 & $\begin{array}{l}\text { Patrimônio } \\
\text { Líquido }\end{array}$ & 110.471 & 117.301 & 121.342 \\
\hline Investimentos & 14.121 & 15.472 & 16.980 & Capital social & 95.298 & 100.229 & 104.419 \\
\hline $\begin{array}{l}\text { Imobilizado de } \\
\text { uso }\end{array}$ & 7.598 & 9.612 & 9.230 & $\begin{array}{l}\text { Reservas de } \\
\text { sobras }\end{array}$ & 11.259 & 13.257 & 16.923 \\
\hline Intangível & 249 & 144 & 39 & $\begin{array}{l}\text { Sobras } \\
\text { acumuladas }\end{array}$ & 3.914 & 3.815 & 0 \\
\hline Total do ativo & 671.808 & 804.062 & 902.041 & $\begin{array}{l}\text { Total do } \\
\text { passivo + PL }\end{array}$ & 671.808 & 804.062 & 902.041 \\
\hline
\end{tabular}

Fonte: Elaborado pelos autores (2019). 
Para elucidar a demonstração contábil apresentada acima, exibida também a demonstração de sobras e perdas, onde foi possível perceber como estava o desempenho da cooperativa, comparando com os resultados dos dois últimos exercícios, conforme é apresentado na tabela 2.

Tabela 2: Demonstração de Sobras ou Perdas

\begin{tabular}{l|l|l|l}
\hline & $\mathbf{2 0 1 5}$ & $\mathbf{2 0 1 6}$ & $\mathbf{2 0 1 7}$ \\
\hline Ingresso da intermediação financeira & $\mathbf{1 1 0 . 9 1 8}$ & $\mathbf{1 3 3 . 7 0 0}$ & $\mathbf{1 2 2 . 1 7 1}$ \\
\hline Operações de crédito & 92.552 & 103.611 & 90.495 \\
\hline Ingresso de depósitos intercooperativos & 18.366 & 30.089 & 31.676 \\
\hline Dispêndios da intermediação financeira & -70.475 & $-\mathbf{9 2 . 0 5 0}$ & $-\mathbf{9 3 . 2 4 8}$ \\
\hline Operações de captação no mercado & -54.412 & -73.603 & -71.295 \\
\hline $\begin{array}{l}\text { Provisão para operações de crédito de liquidação } \\
\text { duvidosa }\end{array}$ & -16.063 & -18.447 & \\
\hline Resultado bruto da intermediação financeira & $\mathbf{4 0 . 4 4 3}$ & $\mathbf{4 1 . 6 5 0}$ & $\mathbf{2 1 . 9 5 3}$ \\
\hline Outros (dispêndios) ingressos operacionais & $-\mathbf{3 5 . 9 6 6}$ & $\mathbf{- 3 3 . 0 9 2}$ & $-\mathbf{2 5 . 9 3 1}$ \\
\hline Ingressos de prestação de serviços & 9.976 & 14.750 & 19.836 \\
\hline Dispêndios de pessoal e honorários & -17.851 & -19.832 & -18.446 \\
\hline Outros dispêndios administrativos & -20.102 & -28.510 & -30.064 \\
\hline Dispêndios tributários & -378 & -549 & -449 \\
\hline Outros dispêndios operacionais & -11.318 & -4.048 & -3.261 \\
\hline Outros ingressos operacionais & 3.707 & 5.097 & 6.453 \\
\hline Resultado operacional & $\mathbf{4 . 4 7 7}$ & $\mathbf{8 . 5 5 8}$ & $\mathbf{2 . 9 9 2}$ \\
\hline Resultado não operacional & -130 & -3.787 & -2.992 \\
\hline Resultado antes da tributação & $\mathbf{4 . 3 4 7}$ & $\mathbf{4 . 7 7 1}$ & $\mathbf{0}$ \\
\hline
\end{tabular}

Fonte: Elaborado pelos autores (2019).

Pela primeira vez em muitos anos, 2017 não fechou com saldo positivo e esse resultado teve como consequência a não distribuição de sobras para os cooperados e a não participação nos lucros para os colaboradores.

Tal informação pegou a todos de surpresa, pois apesar de a cooperativa ser uma instituição financeira sem fins lucrativos, a sua carteira de cooperados era muito exigente, principalmente os cooperados mais antigos que sempre contaram com as sobras e os juros ao capital distribuídos no final de cada exercício.

Enquanto Alfredo explicava o resultado, o mesmo era projetado e os cooperados já começavam a ficar inquietos, iniciando os burburinhos. Dr. Pedro, um dos cooperados fundadores da Coopcred, uma pessoa muito justa e respeitada, levantou sua mão e questionou o que aconteceu e por quê a cooperativa não conseguiu gerar sobras naquele ano.

Tal iniciativa fez com que outros cooperados tomassem coragem e questionassem o que eles não entendiam. Entre eles estava o contador José que perguntou o motivo de as despesas aumentarem o dobro em apenas dois anos, bem como questionou com o que tanto a cooperativa estava gastando. A professora Bete quis saber sobre as operações de crédito, qual a causa de terem sido menores do que o ano de 2015.

Alfredo respirou fundo, pois sabia que seria difícil explicar a situação para os associados, e chamou atenção dos cooperados para o fato de que a cooperativa não ter apresentado prejuízo, já que o resultado ficou praticamente zerado, onde tudo o que foi arrecadado foi desembolsado para os dispêndios.

Quando os ruídos sobre a não distribuição de sobras começou a se acalmar, Dr. Thiago, médico, jovem e muito ligado a tecnologia e inovações, manifestou-se. Ele acompanhava as 
notícias e as transformações que o mercado financeiro vinha passando e questionou os diretores sobre qual teria sido a estratégia da Coopcred para se manter no mercado frente a tantas mudanças, visto que uma das atratividades oferecidas pelo novo modelo de mercado é o serviço com baixo custo e maior acessibilidade.

Os questionamentos do Dr. Thiago, foram os suficientes para que o Dr. Comiotto, um cooperado conservador com alto poder de investimento e muito influente na sua área, se manifestasse em relação às mudanças que a cooperativa vinha enfrentando. Ele notara que algumas mudanças já vinham ocorrendo, como a utilização dos canais de autoatendimento, redução no número de gerentes de relacionamento e alteração no horário de atendimento presencial nos caixas. Para ele, um sinal de que os negócios iam bem era quando as agências estavam cheias, com muitos funcionários na área de atendimento e filas no caixa. O uso da tecnologia ainda não era muito confiável e o incomodava, pois estava encontrando nas agências resistência para executar algumas operações, em virtude de as mesmas serem agora realizadas pelos meios eletrônicos.

Após a manifestação dos dois cooperados, iniciou-se um tumulto, onde alguns concordavam com o Dr. Thiago, e outros associados mais antigos apoiavam as colocações do Dr. Comiotto.

Alfredo e Jorge se entreolharam, e perceberam que os associados estavam divididos assim como eles dois. Parte defendia a manutenção da tradição e cultura da cooperativa, enquanto a outra ala pregava modernizar para crescer.

Neste momento os diretores perceberam que o mais importante era definir os rumos para a Coopcred, que garantisse crescimento sustentável e satisfação aos associados, pregando a união, prática do cooperativismo.

Conseguiriam Alfredo e Jorge construir uma visão conjunta da situação da Coopcred? Qual o melhor caminho para a Coopcred, manter a cultura que orgulhava os sócios mais antigos ou migrar para a era tecnológica, modernizando a cooperativa? Estaria afinal das contas, a Coopcred, passando por uma crise?

\section{NOTAS DE ENSINO}

\section{Objetivos Educacionais}

O caso tem por objetivo demonstrar a importância de analisar as demonstrações contábeis para fins gerenciais e de que maneira elas podem auxiliar nas tomadas de decisões, apresentando dados esclarecedores sobre a situação atual das instituições por meio de uma cooperativa de crédito. Ao realizar esta análise pode-se perceber os pontos fracos e fortes do desempenho operacional e financeiro da entidade estudada.

Com os dados levantados, torna-se possível evidenciar e confrontar informações de uma organização, evidenciando assim seus aspectos relativos à realidade econômica e patrimonial. Estes fatores visam a ascensão e saúde financeira da organização, além de servir como base para metas e estratégias de um futuro próximo.

\section{Utilização Recomendada}

O caso foi desenvolvido para ser utilizado em cursos de graduação em Administração e Ciências Contábeis, ou em cursos de pós-graduação que contenham as disciplinas de Contabilidade Gerencial e Administração Financeira. 


\section{Fontes de Dados}

Os dados apresentados neste caso de ensino foram criados de forma lúdica, sendo nomes e personagens fictícios.

As fontes utilizadas são as conversas entre os autores e professores do curso de pósgraduação na área de ciências sociais, experiências vivenciadas pelos autores, bem como dados secundários disponibilizados em artigos e livros da área.

\section{Plano de Aula}

Sugere-se que o caso para ensino seja disponibilizado com referências bibliográficas relacionadas ao tema para compor a base teórica, com uma semana de antecedência. 0 professor pode solicitar a entrega da resolução individual das questões, a fim de avaliar e acompanhar o desenvolvimento do aluno. Visando auxiliar o professor na aplicação do caso de ensino em sala de aula, aconselha-se seguir o roteiro abaixo.

\begin{tabular}{|c|c|c|}
\hline Tempo Estimado & Atividade & Conceitos Mobilizados \\
\hline $15-20 \mathrm{~min}$ & $\begin{array}{l}\text { Leitura do caso de ensino pelos } \\
\text { estudantes. }\end{array}$ & \\
\hline $05-10 \mathrm{~min}$ & $\begin{array}{l}\text { Apresentação geral do caso, examinando } \\
\text { seus objetivos. }\end{array}$ & Objetivos. \\
\hline $05-10 \mathrm{~min}$ & $\begin{array}{l}\text { Discussão e contextualização sobre a } \\
\text { situação da cooperativa. }\end{array}$ & $\begin{array}{l}\text { Contexto do início da crise financeira, do } \\
\text { novo modelo do mercado financeiro e da } \\
\text { importância do cooperado frente a } \\
\text { cooperativa. }\end{array}$ \\
\hline $60-90 \mathrm{~min}$ & $\begin{array}{l}\text { Divisão da turma em grupos de } 4 \text { a } 5 \\
\text { estudantes para que sejam respondidas as } \\
\text { questões propostas pelo caso. }\end{array}$ & $\begin{array}{l}\text { - Análise horizontal e vertical. } \\
\text { - Situação econômica e financeira. } \\
\text { - Alavancagem. } \\
\text { - Índice da Basileia. }\end{array}$ \\
\hline $45-60 \min$ & $\begin{array}{l}\text { Fechamento da aula. Sugere-se que as } \\
\text { carteiras dos alunos sejam dispostas em } \\
\text { um círculo, para que todos consigam } \\
\text { interagir e que seja iniciada uma conversa, } \\
\text { onde cada grupo exponha e argumente } \\
\text { suas respostas, e que os outros grupos } \\
\text { possam também apresentar suas opiniões, } \\
\text { além do professor. }\end{array}$ & $\begin{array}{l}\text { Decisões das equipes sobre a saúde } \\
\text { financeira da cooperativa e estratégias de } \\
\text { gerenciamento. }\end{array}$ \\
\hline
\end{tabular}

Fonte: Elaborado pelos autores (2019).

Com esta divisão, o professor conseguirá destinar melhor a duração de sua aula, aproveitando-a ao máximo, sem prejudicar o rendimento de seus estudantes, evidenciandose que as sugestões poderão ser modificadas a critério do professor, para melhor aderência a seu plano de ensino.

\section{Questões para discussão}

1) A partir do balanço patrimonial e demonstração de resultado fornecidos pela cooperativa, realize a análise horizontal e vertical destas demonstrações. Explique o 
objetivo destas análises e com base nos resultados, comente por que a cooperativa não conseguiu gerar sobras.

2) Calcule os índices de rentabilidade da cooperativa: margem líquida, retorno sobre o investimento e o retorno sobre o patrimônio líquido. Com as informações obtidas realize a análise da situação econômica da cooperativa e avalie sua capacidade de gerar resultado.

3) Efetue os cálculos dos índices de estrutura (participação de capital de terceiros e composição do endividamento) e os índices de liquidez (liquidez corrente e liquidez geral) para medir a situação financeira da cooperativa.

4) Ao comparar as demonstrações da organização cooperativa com outra organização convencional, como a padaria da esquina por exemplo, percebe-se diferenças. Até mesmo realizando uma análise por meio de índices, se não forem escolhidos os índices corretos, a padaria terá melhores resultados que a cooperativa. Explique o porquê isso ocorre.

5) Há uma norma regulamentadora que as instituições financeiras devem seguir, o Índice de Basileia, que é o índice que mede a solvência de determinada IF. Se uma IF possui Índice de Basileia de $30 \%$, significa que, para cada $\mathrm{R} \$ 100,00$ emprestados, a IF possui patrimônio de $\mathrm{R} \$ 30,00$. O índice mínimo exigido pelo Banco Central do Brasil é 11\%. Com estas informações e analisando a tabela abaixo com os índices, em qual instituição você investiria? Justifique.

Tabela 3 - Índices da Basileia

\begin{tabular}{c|c|c}
\hline Instituição Financeira & Índice de Basileia & Rendimentos em \% do CDI \\
\hline Viacredi & $35,45 \%$ & $96 \%$ \\
\hline Caixa Econômica & $34,07 \%$ & $95 \%$ \\
\hline CoopCred & $23,11 \%$ & $98 \%$ \\
\hline Santander & $15,83 \%$ & $97 \%$ \\
\hline Sicoob & $10,56 \%$ & $100 \%$ \\
\hline
\end{tabular}

Fonte: Elaborado pelos autores (2019).

\section{ANÁLISE DO CASO E CONEXÃO COM A LITERATURA}

Para responder às questões propostas nestas notas de ensino, se faz necessário efetuar uma revisão bibliográfica sobre demonstrações contábeis, análise financeira e de balanços.

As demonstrações contábeis têm por finalidade a representação das informações dos fatos que alterem o patrimônio da entidade. Os índices financeiros são relações entre contas e grupos de demonstrações contábeis que expõem dados fáceis de serem visualizados e de forma direta para uma análise (Silva, 2004).

Além de prestar informações confiáveis e fidedignas, elas podem ser um canal de comunicação com os usuários, estes podem ser tanto internos quanto externos. As demonstrações possibilitam incontáveis avaliações, por isso é necessário compreender o que cada demonstração representa, sua estrutura e o modo em que elas são preparadas. É indispensável também ter conhecimento das práticas utilizada pela entidade e o que cada informação representa. 
Questão 1 - A partir do balanço patrimonial e demonstração de resultado fornecidos pela cooperativa, realize a análise horizontal e vertical destas demonstrações. Explique o objetivo destas análises e com base nos resultados, comente porque a cooperativa não conseguiu gerar sobras.

As análises vertical e horizontal são instrumentos que tendem a identificar tendências para a empresa, com base no seu comportamento ao longo do tempo. De acordo com Assaf Neto (2015), a comparação norteia as análises de balanços e são características de análise empresarial a comparação de valores obtidos em determinado período versus períodos anteriores e a relação desses valores com outros relacionados.

Embora seja possível chegar a resultados similares nas análises horizontal e vertical uma não deve substituir a outra, uma vez que se complementam e permitem ao gestor uma melhor visão sobre os acontecimentos e evoluções da entidade (ASSAF NETO, 2015).

A Análise Horizontal ( $\mathrm{AH}$ ) é realizada abaixo nas tabelas 4 e $5 \mathrm{com}$ base nas informações apresentadas no caso, nas tabelas 1 e 2 , e verifica a evolução das contas durante os períodos, onde seu objetivo é analisar se os valores cresceram ou diminuíram em comparação a períodos anteriores. São analisadas as linhas das demonstrações, ou seja, são comparados os mesmos elementos, mas em anos diferentes. $\mathrm{Na}$ AH será utilizado o ano de 2015 como ano base.

Tabela 4 - Análise Horizontal do Balanço Patrimonial

\begin{tabular}{|c|c|c|c|c|c|}
\hline Ativo & 2015 & 2016 & $\mathrm{AH}$ & 2017 & AH \\
\hline Circulante & 320.970 & 474.411 & $48 \%$ & 594.527 & $25 \%$ \\
\hline Disponibilidades & 3.310 & 2.682 & $-19 \%$ & 3.185 & $19 \%$ \\
\hline Relações interfinanceiras & 173.538 & 282.402 & $63 \%$ & 388.030 & $37 \%$ \\
\hline Operações de crédito & 127.571 & 138.564 & $9 \%$ & 145.687 & $5 \%$ \\
\hline Outros Créditos & 998 & 6.668 & $568 \%$ & 4.334 & $-35 \%$ \\
\hline Outros valores e Bens & 15.553 & 44.095 & $184 \%$ & 53.291 & $21 \%$ \\
\hline Não Circulante & 350.838 & 329.651 & $-6 \%$ & 307.514 & $-7 \%$ \\
\hline Operações de crédito & 325.938 & 299.354 & $-8 \%$ & 275.717 & $-8 \%$ \\
\hline Outros créditos & 2.932 & 5.069 & $73 \%$ & 5.548 & $9 \%$ \\
\hline Investimentos & 14.121 & 15.472 & $10 \%$ & 16.980 & $10 \%$ \\
\hline Imobilizado de uso & 7.598 & 9.612 & $27 \%$ & 9.230 & $-4 \%$ \\
\hline Intangível & 249 & 144 & $-42 \%$ & 39 & $-73 \%$ \\
\hline Total do ativo & 671.808 & 804.062 & $20 \%$ & 902.041 & $12 \%$ \\
\hline Passivo & 2015 & 2016 & $\mathrm{AH}$ & 2017 & $\mathbf{A H}$ \\
\hline Circulante & 558.293 & 681.606 & $22 \%$ & 773.689 & $14 \%$ \\
\hline Depósitos & 551.740 & 675.051 & $22 \%$ & 762.152 & $13 \%$ \\
\hline Relações interfinanceiras & 0 & 0 & $0 \%$ & 243 & $0 \%$ \\
\hline Outras obrigações & 6.553 & 6.555 & $0 \%$ & 11.294 & $72 \%$ \\
\hline Não Circulante & 3.044 & 5.155 & $69 \%$ & 7.010 & $36 \%$ \\
\hline Outras obrigações & 3.044 & 5.155 & $69 \%$ & 7.010 & $36 \%$ \\
\hline Patrimônio Líquido & 110.471 & 117.301 & $6 \%$ & 121.342 & $3 \%$ \\
\hline Capital social & 95.298 & 100.229 & $5 \%$ & 104.419 & $4 \%$ \\
\hline Reservas de sobras & 11.259 & 13.257 & $18 \%$ & 16.923 & $28 \%$ \\
\hline Sobras acumuladas & 3.914 & 3.815 & $-3 \%$ & 0 & $0 \%$ \\
\hline Total do passivo + PL & 671.808 & 804.062 & $20 \%$ & 902.041 & $12 \%$ \\
\hline
\end{tabular}

Fonte: Elaborado pelos autores (2019). 
Tabela 5 - Análise Horizontal da Demonstração de Sobras ou Perdas

\begin{tabular}{|c|c|c|c|c|c|}
\hline & 2015 & 2016 & $\mathbf{A H}$ & 2017 & $\mathbf{A H}$ \\
\hline Ingresso da intermediação financeira & 110.918 & 133.700 & $21 \%$ & 122.171 & $-9 \%$ \\
\hline Operações de crédito & 92.552 & 103.611 & $12 \%$ & 90.495 & $-13 \%$ \\
\hline Ingresso de depósitos intercooperativos & 18.366 & 30.089 & $64 \%$ & 31.676 & $5 \%$ \\
\hline Dispêndios da intermediação financeira & -70.475 & -92.050 & $31 \%$ & -93.248 & $1 \%$ \\
\hline Operações de captação no mercado & -54.412 & -73.603 & $35 \%$ & -71.295 & $-3 \%$ \\
\hline $\begin{array}{l}\text { Provisão para operações de crédito de } \\
\text { liquidação duvidosa }\end{array}$ & -16.063 & -18.447 & $15 \%$ & -21.953 & $19 \%$ \\
\hline Resultado bruto da intermediação financeira & 40.443 & 41.650 & $3 \%$ & 28.923 & $-31 \%$ \\
\hline Outros (dispêndios) ingressos operacionais & -35.966 & -33.092 & $-8 \%$ & -25.931 & $-22 \%$ \\
\hline Ingressos de prestação de serviços & 9.976 & 14.750 & $48 \%$ & 19.836 & $34 \%$ \\
\hline Dispêndios de pessoal e honorários & -17.851 & -19.832 & $11 \%$ & -18.446 & $-7 \%$ \\
\hline Outros dispêndios administrativos & -20.102 & -28.510 & $42 \%$ & -30.064 & $5 \%$ \\
\hline Dispêndios tributários & -378 & -549 & $45 \%$ & -449 & $-18 \%$ \\
\hline Outros dispêndios operacionais & -11.318 & -4.048 & $-64 \%$ & -3.261 & $-19 \%$ \\
\hline Outros ingressos operacionais & 3.707 & 5.097 & $37 \%$ & 6.453 & $27 \%$ \\
\hline Resultado operacional & 4.477 & 8.558 & $91 \%$ & 2.992 & $-65 \%$ \\
\hline Resultado não operacional & -130 & -3.787 & $2813 \%$ & -2.992 & $-21 \%$ \\
\hline Resultado antes da tributação & 4.347 & 4.771 & $10 \%$ & 0 & $0 \%$ \\
\hline Imposto de renda e contribuição social & -433 & -20 & $-95 \%$ & 0 & $0 \%$ \\
\hline
\end{tabular}

Tabela 5 - Análise Horizontal da Demonstração de Sobras ou Perdas (continuação)

\begin{tabular}{l|l|l|l|l|l}
\hline & 2015 & 2016 & AH & 2017 & AH \\
\hline Sobra do semestre/exercício & 3.914 & 4.751 & $21 \%$ & 0 & $0 \%$ \\
\hline Resultado operacional & 4.477 & 8.558 & $91 \%$ & 2.992 & $-65 \%$ \\
\hline
\end{tabular}

Fonte: Elaborado pelos autores (2019).

Já a Análise Vertical (AV) apresentada abaixo na tabela 6, tem por objetivo medir percentualmente de cada componente a participação de determinado indicador no resultado. Nela são analisadas as colunas das demonstrações e apresenta o quanto cada conta é importante em relação à demonstração financeira a que pertence. Na AV da DRE deve-se considerar $100 \%$ a receita bruta e no balanço o total de ativo/passivo.

Estas análises são importantes para os associados para que os mesmos possam realizar uma análise comparativa, relacionando o quanto que as sobras representam da receita da intermediação financeira, por exemplo, e, também a evolução das contas ao longo do tempo, como o crescimento das receitas, das sobras, da evolução do patrimônio. 
Tabela 6 - Análise Vertical do Balanço Patrimonial

\begin{tabular}{|c|c|c|c|c|c|c|}
\hline Ativo & 2015 & AV & 2016 & AV & 2017 & AV \\
\hline Circulante & 320.970 & $48 \%$ & 474.411 & $59 \%$ & 594.527 & $66 \%$ \\
\hline Disponibilidades & 3.310 & $0 \%$ & 2.682 & $0 \%$ & 3.185 & $0 \%$ \\
\hline Relações interfinanceiras & 173.538 & $26 \%$ & 282.402 & $35 \%$ & 388.030 & $43 \%$ \\
\hline Operações de crédito & 127.571 & $19 \%$ & 138.564 & $17 \%$ & 145.687 & $16 \%$ \\
\hline Outros Créditos & 998 & $0 \%$ & 6.668 & $1 \%$ & 4.334 & $0 \%$ \\
\hline Outros valores e Bens & 15.553 & $2 \%$ & 44.095 & $5 \%$ & 53.291 & $6 \%$ \\
\hline Não Circulante & 350.838 & $52 \%$ & 329.651 & $41 \%$ & 307.514 & $34 \%$ \\
\hline Operações de crédito & 325.938 & $49 \%$ & 299.354 & $37 \%$ & 275.717 & $31 \%$ \\
\hline Outros créditos & 2.932 & $0 \%$ & 5.069 & $1 \%$ & 5.548 & $1 \%$ \\
\hline Investimentos & 14.121 & $2 \%$ & 15.472 & $2 \%$ & 16.980 & $2 \%$ \\
\hline Imobilizado de uso & 7.598 & $1 \%$ & 9.612 & $1 \%$ & 9.230 & $1 \%$ \\
\hline Intangível & 249 & $0 \%$ & 144 & $0 \%$ & 39 & $0 \%$ \\
\hline Total do ativo & 671.808 & $100 \%$ & 804.062 & $100 \%$ & 902.041 & $100 \%$ \\
\hline Passivo & 2015 & AV & 2016 & AV & 2017 & AV \\
\hline Circulante & 558.293 & $83 \%$ & 681.606 & $85 \%$ & 773.689 & $86 \%$ \\
\hline Depósitos & 551.740 & $82 \%$ & 675.051 & $84 \%$ & 762.152 & $84 \%$ \\
\hline Relações interfinanceiras & 0 & $0 \%$ & 0 & $0 \%$ & 243 & $0 \%$ \\
\hline Outras obrigações & 6.553 & $1 \%$ & 6.555 & $1 \%$ & 11.294 & $1 \%$ \\
\hline Não Circulante & 3.044 & $0 \%$ & 5.155 & $1 \%$ & 7.010 & $1 \%$ \\
\hline Outras obrigações & 3.044 & $0 \%$ & 5.155 & $1 \%$ & 7.010 & $1 \%$ \\
\hline Patrimônio Líquido & 110.471 & $16 \%$ & 117.301 & $15 \%$ & 121.342 & $13 \%$ \\
\hline Capital social & 95.298 & $14 \%$ & 100.229 & $12 \%$ & 104.419 & $12 \%$ \\
\hline Reservas de sobras & 11.259 & $2 \%$ & 13.257 & $2 \%$ & 16.923 & $2 \%$ \\
\hline Sobras acumuladas & 3.914 & $1 \%$ & 3.815 & $0 \%$ & 0 & $0 \%$ \\
\hline Total do passivo + PL & 671.808 & $100 \%$ & 804.062 & $100 \%$ & 902.041 & $100 \%$ \\
\hline
\end{tabular}

Fonte: Elaborado pelos autores (2019).

Com base ainda nas informações da tabela 2, efetua-se na tabela 7 a análise vertical e pode-se verificar que o ingresso da intermediação financeira representa apenas $91 \%$ do resultado do ano anterior 2016 e os dispêndios quase não tiveram alterações. A conta de provisão para operações de crédito de liquidação duvidosa representa $18 \%$ da receita e aumentou quase $R \$ 3,5$ milhões, é uma conta que deve ser trabalhada pela cooperativa para que pelo menos fique estabilizada (controlada). 
Tabela 7 - Análise Vertical da Demonstração de Sobras ou Perdas

\begin{tabular}{|c|c|c|c|c|c|c|}
\hline & 2015 & AV & 2016 & AV & 2017 & AV \\
\hline Ingresso da intermediação financeira & 110.918 & $100 \%$ & 133.700 & $100 \%$ & 122.171 & $100 \%$ \\
\hline Operações de crédito & 92.552 & $83 \%$ & 103.611 & $77 \%$ & 90.495 & $74 \%$ \\
\hline Ingresso de depósitos intercooperativos & 18.366 & $17 \%$ & 30.089 & $23 \%$ & 31.676 & $26 \%$ \\
\hline Dispêndios da intermediação financeira & -70.475 & $-64 \%$ & -92.050 & $-69 \%$ & -93.248 & $-76 \%$ \\
\hline Operações de captação no mercado & -54.412 & $-49 \%$ & -73.603 & $-55 \%$ & -71.295 & $-58 \%$ \\
\hline $\begin{array}{l}\text { Provisão para operações de crédito de } \\
\text { liquidação duvidosa }\end{array}$ & -16.063 & $-14 \%$ & -18.447 & $-14 \%$ & -21.953 & $-18 \%$ \\
\hline $\begin{array}{l}\text { Resultado bruto da intermediação } \\
\text { financeira }\end{array}$ & 40.443 & $36 \%$ & 41.650 & $31 \%$ & 28.923 & $24 \%$ \\
\hline Outros (dispêndios) ingressos operacionais & -35.966 & $-32 \%$ & -33.092 & $-25 \%$ & -25.931 & $-21 \%$ \\
\hline Ingressos de prestação de serviços & 9.976 & $9 \%$ & 14.750 & $11 \%$ & 19.836 & $16 \%$ \\
\hline Dispêndios de pessoal e honorários & -17.851 & $-16 \%$ & -19.832 & $-15 \%$ & -18.446 & $-15 \%$ \\
\hline Outros dispêndios administrativos & -20.102 & $-18 \%$ & -28.510 & $-21 \%$ & -30.064 & $-25 \%$ \\
\hline Dispêndios tributários & -378 & $0 \%$ & -549 & $0 \%$ & -449 & $0 \%$ \\
\hline Outros dispêndios operacionais & -11.318 & $-10 \%$ & -4.048 & $-3 \%$ & -3.261 & $-3 \%$ \\
\hline Outros ingressos operacionais & 3.707 & $3 \%$ & 5.097 & $4 \%$ & 6.453 & $5 \%$ \\
\hline Resultado operacional & 4.477 & $4 \%$ & 8.558 & $6 \%$ & 2.992 & $2 \%$ \\
\hline Resultado não operacional & -130 & $0 \%$ & -3.787 & $-3 \%$ & -2.992 & $-2 \%$ \\
\hline Resultado antes da tributação & 4.347 & $4 \%$ & 4.771 & $4 \%$ & 0 & $0 \%$ \\
\hline Imposto de renda e contribuição social & -433 & $0 \%$ & -20 & $0 \%$ & 0 & $0 \%$ \\
\hline Sobra do semestre/exercício & 3.914 & $4 \%$ & 4.751 & $4 \%$ & 0 & $0 \%$ \\
\hline
\end{tabular}

Fonte: Elaborado pelos autores (2019).

Como a receita foi menor que o ano anterior e as despesas permaneceram quase que as mesmas, entende-se que por isso a cooperativa não conseguiu gerar lucro/sobras. Devem empenhar-se para maximizar as receitas, podendo criar novas linhas de crédito, captar novos cooperados e recursos, oferecer novos produtos e serviços, entre outros.

Questão 2 - Calcule os índices de rentabilidade da cooperativa: margem líquida, retorno sobre o investimento e o retorno sobre o patrimônio líquido. Com as informações obtidas realize a análise da situação econômica da cooperativa e avalie sua capacidade de gerar resultado.

Uma instituição financeira atua operacionalmente com base em duas grandes decisões financeiras: investimentos/aplicações (ativo) e financiamento/captações (passivo). O spread bancário é considerado o resultado bruto de suas operações, que consiste nas receitas da intermediação financeira menos as despesas com intermediação financeira.

Para Assaf Neto (2015) o comportamento das atividades bancárias compara-se ao comportamento de outros negócios, e os inputs em uma instituição financeira são os recursos captados que serão negociados sob a forma de créditos e empréstimos concedidos e investimentos.

Como todo negócio, as instituições financeiras buscam maximizar a riqueza de seus proprietários com uma relação de risco e retorno.

Todos os índices calculados nesta questão e demonstrados na tabela 8, possuem a interpretação de quanto maior (mais perto de 1,00), melhor, e utilizaram as informações apresentadas quadro 2 do caso. 
A margem líquida é formada pelos resultados obtidos da manipulação dos ativos e passivos das instituições financeiras (taxas, prazos, receitas e despesas), e possibilitam avaliar a função básica de intermediação financeira de um banco (ASSAF NETO, 2015).

Tabela 8 - Análise da Situação Econômica

\begin{tabular}{|c|c|c|c|c|c|c|c|}
\hline \multirow[b]{2}{*}{$\begin{array}{l}\text { Margem } \\
\text { líquida: }\end{array}$} & \multirow[b]{2}{*}{$\begin{array}{c}\text { Sobras líquidas } \\
\text { Receita de } \\
\text { intermediação } \\
\text { financeira }\end{array}$} & \multicolumn{2}{|c|}{2015} & \multicolumn{2}{|c|}{2016} & \multicolumn{2}{|c|}{2017} \\
\hline & & $\begin{array}{c}3.914 \\
110.918\end{array}$ & 0,0353 & $\begin{array}{c}\underline{4.751} \\
133.700\end{array}$ & 0,0355 & $\begin{array}{c}\underline{0} \\
122.171\end{array}$ & 0,0000 \\
\hline $\begin{array}{l}\text { Retorno sobre o } \\
\text { investimento: }\end{array}$ & $\frac{\text { Sobras líquidas }}{\text { Ativo }}$ & $\begin{array}{l}\underline{3.914} \\
671.808\end{array}$ & 0,0058 & $\begin{array}{c}\underline{4.751} \\
804.062\end{array}$ & 0,0059 & $\begin{array}{c}\underline{0} \\
902.041\end{array}$ & 0,0000 \\
\hline $\begin{array}{l}\text { Retorno sobre o } \\
\text { patrimônio } \\
\text { líquido: }\end{array}$ & Sobras líquidas & $\begin{array}{c}\underline{3.914} \\
110.471\end{array}$ & 0,0354 & $\begin{array}{c}4.751 \\
117.301\end{array}$ & 0,0405 & $\begin{array}{c}\underline{0} \\
121.342\end{array}$ & 0,0000 \\
\hline
\end{tabular}

Fonte: Elaborado pelos autores baseados em Assaf Neto (2015).

Novamente percebe-se estabilidade nos anos de 2015 e 2016 com pouca variação. E em 2017 como não houveram sobras, não foi possível calcular o índice. No retorno sobre o investimento nota-se que variou apenas 0,0001 de 2015 para 2016 e que em 2017 não houve como calcular o índice.

O retorno sobre o investimento demonstra claramente os resultados das oportunidades de negócios acionadas pelas instituições financeiras sendo uma medida de eficiência influenciada principalmente pela qualidade do gerenciamento da lucratividade dos ativos e juros passivos (ASSAF NETO, 2015)

Já no retorno sobre o patrimônio líquido Assaf Neto (2015) afirma que o mesmo fornece o ganho percentual alcançado como uma consequência das margens de lucro, da eficiência operacional e do planejamento eficiente dos negócios. Com este índice os cooperados conseguem mensurar o quanto de lucro a companhia gera com o dinheiro investido por eles no capital da cooperativa e é utilizado também para comparar a rentabilidade de uma outra empresa do mesmo setor. Observa-se que de 2015 para 2016 houve um crescimento de $114 \%$ e em 2017 o índice foi zerado.

A rentabilidade de uma empresa é medida em relação às vendas, ou seja, é a mensuração da capacidade de uma entidade em reduzir custos e despesas a fim transformar o máximo possível das vendas em lucro.

Para Ferreira, Gonçalves e Braga (2007), a eficiência das cooperativas está associada à capacidade de maximização de seus benefícios aos associados, transformados em operações de créditos e benefícios líquidos, em contrapartida aos recursos empregados para sua obtenção.

A cooperativa vinha gerando e mantendo um bom resultado, mas como 2017 ele foi zerado, deve-se trabalhar para alavancar seus negócios e não gerar tendências. Não se pode qualificar o resultado obtido como ruim de imediato, algumas questões devem ser levantadas, como por exemplo, não há a informação sobre a rentabilidade de outras cooperativas que atuam na mesma região. 
Essa seria uma informação importante para poder comparar as cooperativas e classificá-las em um ranking, medindo seu desempenho. Outro ponto é que a rentabilidade pode ser baixa, desde que seja suficiente para a mesma se manter no mercado e garantir sua competitividade (REIS, 2006).

Questão 3 - Efetue os cálculos dos índices de estrutura (participação de capital de terceiros e composição do endividamento) e os índices de liquidez (liquidez corrente e liquidez geral) para medir a situação financeira da cooperativa.

A análise financeira realizada na tabela 9 segue de acordo com os índices propostos por Matarazzo (2010), que promovem a compreensão da relação entre ativos e passivos, disponíveis e obrigações. Utilizaram-se as informações do balanço patrimonial apresentadas na tabela 1 do caso.

Tabela 9 - Análise da Situação Financeira

\begin{tabular}{|c|c|c|c|c|c|c|c|}
\hline \multirow{3}{*}{$\begin{array}{l}\text { Participação de capitais } \\
\text { de terceiros: }\end{array}$} & \multirow{3}{*}{$\frac{P C+P n C \times 100}{P L}$} & \multicolumn{2}{|c|}{2015} & \multicolumn{2}{|c|}{2016} & \multicolumn{2}{|c|}{2017} \\
\hline & & \multirow{2}{*}{$\frac{561.337}{110.471}$} & \multirow{2}{*}{$508 \%$} & \multirow{2}{*}{$\frac{686.761}{117.301}$} & \multirow{2}{*}{$585 \%$} & \multirow{2}{*}{$\frac{780.699}{121.342}$} & \multirow{2}{*}{$643 \%$} \\
\hline & & & & & & & \\
\hline \multirow{2}{*}{$\begin{array}{l}\text { Composição do } \\
\text { endividamento: }\end{array}$} & $\underline{P C \times 100}$ & \multirow{2}{*}{$\frac{558.293}{561.337}$} & \multirow{2}{*}{$99 \%$} & \multirow{2}{*}{$\frac{681.606}{686.761}$} & \multirow{2}{*}{$99 \%$} & 773.689 & \multirow{2}{*}{$99 \%$} \\
\hline & $\mathrm{PC}+\mathrm{PnC}$ & & & & & 780.699 & \\
\hline \multirow{2}{*}{ Liquidez corrente: } & $\underline{A C}$ & \multirow{2}{*}{$\frac{320.970}{558.293}$} & \multirow{2}{*}{0,5749} & 474.411 & \multirow{2}{*}{0,6960} & $\underline{594.527}$ & \multirow{2}{*}{0,7684} \\
\hline & $\mathrm{PC}$ & & & $\overline{681.606}$ & & 773.689 & \\
\hline Liquidez geral: & $\underline{A C}$ & $\frac{320.970}{561.337}$ & 0,5718 & $\frac{474.411}{686.761}$ & 0,6908 & $\frac{594.527}{780.699}$ & 0,7615 \\
\hline
\end{tabular}

Fonte: Elaborado pelos autores com base em Matarazzo (2010).

Os índices de estrutura de capital mostram as linhas de decisões financeiras, em termos de obtenção e aplicação de recursos. Os dois possuem interpretação de que quanto menor, melhor.

A participação de capitais de terceiros indica a quantidade de reais obtidos de terceiros para cada $\mathrm{R} \$ 100,00$ de capital próprio. De acordo com Matarazzo (2010) este índice relaciona as duas grandes fontes de recursos da empresa e pode ser considerado como um indicador de risco ou de dependência a terceiros. Do ponto de vista financeiro, quanto maior a relação de capital de terceiros, há maior dependência a esses terceiros e consequentemente menor liberdade de decisões da empresa.

Nota-se que é um alto índice em todos os anos, e que a cada período vem crescendo: de 2016 para 2015 o aumento foi de 77 pontos percentuais e de 2017 para 2016 o aumento foi de 58 pontos percentuais. Porém a maior dependência ocorreu no ano de 2017.

A composição do endividamento mostra o percentual de obrigações de curto prazo em relação às obrigações totais. Percebe-se que não houve alteração no percentual durante os três anos, o mesmo se manteve em $99 \%$. É de suma importância a empresa conhecer qual a composição de suas dívidas.

As dívidas de curto prazo precisam ser quitadas com os recursos que a empresa possui hoje mais aqueles recursos que foram gerados em curto prazo, já as de longo prazo a entidade desfruta de tempo para a geração de recursos (MATARAZZO, 2010). 
Os índices de liquidez, são a base da situação financeira da empresa, possuem interpretação de que quanto maior, melhor. São indicadores que medem a probabilidade e a capacidade de uma entidade em honrar seus compromissos de curto prazo, no dia de seu vencimento, ou seja, a solidez da estrutura financeira da instituição. Para Assaf Neto (2015), a liquidez dos bancos reflete a capacidade financeira dos mesmos, em atender a demanda por recursos de caixa. Já a posição de liquidez indica a habilidade que uma instituição apresenta em gerar caixa a fim de atender de forma adequada, suas obrigações financeiras.

A liquidez corrente mostra quanto à empresa tem de ativo circulante para cada $R \$ 1,00$ investido no passivo circulante. Repara-se que o índice no caso da Coopcred vem crescendo, porém em nenhum momento foi maior que $\mathrm{R} \$ 1,00$, assim a cooperativa não possui uma margem de folga para equilibrar entradas e saídas. Quanto maior essa margem, maior a segurança da empresa e melhor sua situação financeira.

Por último, a liquidez geral que revela o índice de capacidade de pagamento de dívidas assumidas com terceiros, com o ativo circulante. Constata-se que os indicadores são bem próximos aos da liquidez corrente e que também estão aumentando com o passar dos períodos.

Observa-se que os dois índices de liquidez melhoraram apesar da queda constatada na análise horizontal, devido ao aumento do ativo circulante. Essa sobra de caixa pode ser oriunda de menos crédito/dinheiro emprestado aos cooperados. A curto prazo isso é bom, mas para longo prazo pode ser um problema.

Assim como na questão no 2 não podemos alegar que é um índice ruim, pois não temos como comparar com outras cooperativas, mas vimos que ele está demonstrando uma tendência de crescimento nos últimos anos. A análise de dados financeiros é de grande importância pois mede a saúde financeira da empresa, identificando questões que trazem preocupação ou que indicam bom desempenho da organização.

Questão 4 - Ao comparar as demonstrações da organização cooperativa com outra organização convencional, como a padaria da esquina por exemplo, percebe-se diferenças. Até mesmo realizando uma análise por meio de índices, se não forem escolhidos os índices corretos, a padaria terá melhores resultados que a cooperativa. Explique o porquê isso ocorre.

Ao confrontar as demonstrações contábeis de uma empresa comum com as demonstrações de instituições financeiras, pode-se perceber que as contas contábeis possuem nomenclaturas e grupos diferentes dos habituais. A lógica é a mesma, porém há uma particularidade nas instituições financeiras: a alavancagem.

De acordo com Fernandes (2013), na temática finanças, alavancagem é o termo geralmente utilizado para qualquer técnica aplicada que permita multiplicar a rentabilidade, recorrendo ao endividamento. A análise da alavancagem busca demonstrar a relevância do capital de terceiros na estrutura de capital da entidade, visando maximizar o lucro dos sócios.

As instituições financeiras dedicam-se a dois tipos de atividades, uma em cada lado do balanço patrimonial: captação de depósitos e empréstimos. De acordo com Diamond e Rajan (2001) os bancos realizam atividades valiosas de ambos os lados de seus balanços. No lado do ativo, fazem empréstimos a tomadores, aumentando o fluxo de crédito na economia. No lado do passivo, eles fornecem liquidez sob demanda aos depositantes.

Enquanto as empresas convencionais possuem um passivo e patrimônio líquido que normalmente têm a estrutura com o dobro de capital de terceiros para um de capital próprio, 
o passivo e PL das instituições financeiras não consistem em dívidas, trata-se dos valores depositados pelos correntistas/associados. Essa característica consiste na alavancagem.

É comum medir o índice de alavancagem nas instituições financeiras, onde é mensurado seu capital próprio e o volume de empréstimos realizados aos clientes. Quanto maior o indicador, mais financiamentos a instituição realiza com o mesmo capital.

Por isso, não é possível comparar uma instituição financeira com uma empresa convencional, o ideal é realizar o comparativo com uma empresa do mesmo ramo e setor. Instituições financeiras como bancos, cooperativas, bancos de investimentos, só podem ser comparadas entre si.

Questão 5 - Há uma norma regulamentadora que as instituições financeiras devem seguir, o Índice de Basileia, que é o índice que mede a solvência de determinada IF. Se uma IF possui Índice de Basileia de 30\%, significa que, para cada $\mathrm{R} \$ 100,00$ emprestados, a IF possui patrimônio de $\mathrm{R} \$ 30,00$. O índice mínimo exigido pelo Banco Central do Brasil é $11 \%$. Com estas informações e analisando a tabela abaixo com os índices, em qual instituição você investiria? Justifique.

Tabela 3 - Índices da Basileia

\begin{tabular}{c|c|c}
\hline Instituição Financeira & Índice de Basileia & Rendimentos em \% do CDI \\
\hline Viacredi & $35,45 \%$ & $96 \%$ \\
Caixa Econômica & $34,07 \%$ & $95 \%$ \\
CoopCred & $23,11 \%$ & $98 \%$ \\
Santander & $15,83 \%$ & $97 \%$ \\
Sicoob & $10,56 \%$ & $100 \%$ \\
\hline
\end{tabular}

Fonte: Elaborado pelos autores (2019).

O índice da Basileia foi criado em 1988 e tem por objetivo criar exigências mínimas de capital para instituições financeiras como forma de fazer face ao risco de crédito. Foi estabelecido por meio de um comitê formado por um grupo de especialistas que estudam o sistema financeiro mundial e que buscam reforçar a regulação, supervisão e melhorias práticas no mercado financeiro (BACEN, 2018).

Esse índice mede a saúde financeira de uma instituição, ele determina a relação entre o capital próprio da instituição e o capital de terceiros (captações) que será exposto ao risco por meio da carteira de crédito. Ou seja, se uma instituição possui um índice de $25 \%$ significa que para cada $\mathrm{R} \$ 100,00$ emprestados, $\mathrm{R} \$ 25,00$ pertence a seu patrimônio.

Não há uma resposta correta para a questão, tudo irá depender do risco que o investidor pretende correr. Acompanhar o índice da Basileia é importante quando você nunca ouviu falar sobre a instituição, para verificar se a mesma possui um bom gerenciamento dos seus recursos. Todas as instituições demonstradas no quadro acima possuem um índice acima de $11 \%$, o que significa que estão em um nível seguro de alavancagem.

Dependendo do perfil do investidor ele pode optar por aceitar um risco maior para ter um retorno melhor ou preferir a segurança mesmo que a rentabilidade seja menor. Porém se fosse oferecido o mesmo produto com a mesma rentabilidade, o ideal seria escolher aquela instituição com maior índice, um investimento mais seguro de acordo com esse parâmetro (DUARTE, 2018). 


\section{REFERÊNCIAS}

ASSAF NETO, A. Estrutura e análise de balanços: um enfoque econômico-financeiro. 11. ed. São Paulo: Atlas, 2015.

BACEN, Banco Central do Brasil. Recomendações de Basileia. Disponível em: <https://www.bcb.gov.br/fis/supervisao/basileia.asp>. Acesso em: 25 jul. 2018.

DIAMOND, D. W.; RAJAN, R. G. Liquidity risk, liquidity creation, and financial fragility: a theory of banking. Journal of Political Economy, Chicago, v. 109, n. 2, p. 287-326, 2001. DOI: https://doi.org/10.1086/319552.

DUARTE, D. O que é Basileia e como esse índice mede a solvência de uma instituição. Magnetis, fev. 2018. Disponível em: <https://blog.magnetis.com.br/indice-de-basileia>. Acesso em 25 jul. 2018.

FERNANDES, L. S. S. O risco de alavancagem nas instituições financeiras. 2013. Tese de Doutorado. Instituto Superior de Economia e Gestão.

FERREIRA, M. A. M.; GONÇALVES, R. M. L.; BRAGA, M. J. Investigação do desempenho das cooperativas de crédito de Minas Gerais por meio da Análise Envoltória de Dados (DEA). Economia Aplicada, Ribeirão Preto - SP. v. 11, n. 3, p. 425-445, 2007. DOI: http://dx.doi.org/10.1590/S1413-80502007000300006.

MATARAZZO, D. C. Análise financeira de balanços: abordagem gerencial. 7. ed. São Paulo: Atlas, 2010.

REIS, B. dos S. Análise de balanços em cooperativas - Parte II. Café Point, dez. 2006. Disponível em: <https://www.cafepoint.com.br/noticias/tecnicas-de-producao/analise-de-balancosem-cooperativas-parte-ii-33292n.aspx>. Acesso em: 05 jun. 2018.

SILVA, José Pereira da. Análise Financeira das Empresas. 6 ed. São Paulo: Editora Atlas S.A, 2004. 